\title{
Water retention and characteristic curves representing tropical clay soils from Africa
}

\author{
K.M.A. Alhaj ${ }^{1}$, G. Biscontin ${ }^{1}$, M.Z.E.B Elshafie ${ }^{2}$ and A.S. Osman ${ }^{3}$ \\ ${ }^{1}$ Civil Engineering Department, Cambridge University, United Kingdom \\ ${ }^{2}$ Civil and Architectural Engineering Department, Qatar University, Qatar \\ ${ }^{3}$ Deparment of Engineering, Durham University, United Kingdom
}

\begin{abstract}
Soil water retention curves (SWRCs) form an essential component of frameworks coupling the hydromechanical behaviour of unsaturated soils. The curves describe how suction changes with variables such as degree of saturation, void ratio and volumetric/gravimetric water content. SWRCs can be determined from incrementally drying initially saturated reconstituted samples to a final residual state, thus developing the primary drying curve (PDC). The primary wetting curve (PWC) is established from subsequent incremental wetting from residual state and is hysteretic compared with the PDC. SWRCs for reconstituted, high-plasticity, tropical clays from Africa (Sudan, Tanzania and South Africa) will be produced using suction measuring instruments, a tensiometer, filter paper and a dew point potentiometer. The development of SWRCs under various subsequent cycles of drying will be presented and discussed along with details concerning volumetric changes and cracking during drying. In order to investigate the uniqueness of the PDC and PWC and the effect of initial void ratio, SWRCs will be determined for samples formed by reconstituted from slurry under different applied energy levels.
\end{abstract}

\section{Introduction}

A partially saturated soil is a complex multi-phase system consisting of air, water and solid material whose response is a function of the stress state, moisture condition and other internal variables present within the soil [9]. Many researchers have investigated coupling the hydro-mechanical behaviour of unsaturated soils and several methods have been proposed to predict and estimate their engineering response. Soil suction constitutes an integral part of soil water retention curves (SWRC), which are frequently utilised to investigate the coupled hydromechanical behaviour of unsaturated soils. $[1,6,16]$ highlight the importance of SWRCs in understanding unsaturated soil behaviour. The SWRC is expressed as a relation between the logarithm of suction and either degree of saturation $\mathrm{S}_{\mathrm{r}}$, void ratio $\mathrm{e}$, volumetric water content $\theta_{\mathrm{w}}$, or gravimetric water content, $w$. SWRCs generally have a sigmoidal form and plays a key role in recently proposed constitutive models and have been used to predict the compressibility during virgin loading [10], shear strength [2] and volume change behaviour of unsaturated soil. SWRCs are usually determined experimentally in the laboratory and can then be related to other properties of the unsaturated soil.

Data for developing SWRCs are often obtained by incrementally drying initially saturated, reconstituted samples to a final residual state, at which $S_{r}$ remains constant, thus developing what is often referred to as the primary drying curve (PDC). The wetting-up process can then commence by adding small amounts of water to the sample in incremental stages.

Both drying and wetting curves can be drawn (generally as $\log \mathrm{s}$ versus $\mathrm{S}_{\mathrm{r}}$ ) from these measurements. If drying starts from slurry and wetting from the residual state, the two curves are considered to be boundary curves (primary drying curve PDC and primary wetting curve PWC) and it is often considered that any sample in any condition should lie within these boundaries. However, recent research [4] suggests that a boundary surface may be more appropriate to account for variations in specific volume, $v$. Usually, the end of the wetting curve differs from the starting point of the drying curve (i.e. the soil does not return to a fully saturated state). As the PWC does not follow the path of the PDC the process of drying and wetting is hysteretic. If small wetting and drying cycles take place from positions along the PDC or PWC, intermediate curves are created within the primary curves called scanning curves [13].

For very plastic clays, sometimes it is not possible to develop the full SWRC because of limitations of some suction measurement techniques, e.g. with the filter paper method the maximum suction that can be measured is $-30 \mathrm{MPa}$. In these cases, it is not possible to reach the residual value because the soil has developed very high suctions while the degree of saturation is still relatively high. This is particularly the case for highly plastic clays [13]. 
Numerous formulations are available for mathematically modelling the sigmoidal form of SWRCs. A comprehensive summary of these is given by [6].

The model given by van [15] is commonly used, for which the residual point needs to be defined.

\section{Soil characteristics and samples preparation}

The work presented here forms part of WindAfrica research project which aims to develop new design guidelines for foundations of wind turbines on expansive soils. This paper presents the results of laboratory works conducted at Cambridge University on two natural soils from two locations in Africa: a black cotton clay from Sudan (Al Fao) and Atta clay from Steelpoort, South Africa (SA). One of the aims of the research was to generate SWRCs for the both of clay soils. Basic characteristics of the soils are given in Table 1.

Both soils were reconstituted from slurry in a consolidometer using the procedure described in [12, 14] to a vertical total stress of $200 \mathrm{kPa}$. Six discs for each soil were trimmed from the resulting soil cakes and initial water content and volume measured. The discs were gradually dried, measuring total and matrix suction, in order to obtain the Soil-Water Retention Curve (SWRC) for each soil.

Table 1. Basic soil characteristics.

\begin{tabular}{|c|c|c|}
\hline Soil Type & $\begin{array}{c}\text { Sudanese } \\
\text { clay }\end{array}$ & $\begin{array}{c}\text { South } \\
\text { African clay }\end{array}$ \\
\hline Gravel (\%) & 4 & 3 \\
\hline Sand (\%) & 7 & 21 \\
\hline Silt (\%) & 26 & 67 \\
\hline $\begin{array}{c}\text { Clay (\%) } \\
\text { Liquid limit, } \\
\text { LL: \% }\end{array}$ & 60 & 92 \\
\hline $\begin{array}{c}\text { Plastic limit, } \\
\text { PL: \% }\end{array}$ & 30 & 37 \\
\hline $\begin{array}{c}\text { Plasticity } \\
\text { index, PI: \% }\end{array}$ & 30 & 55 \\
\hline $\begin{array}{c}\text { Activity } \\
\text { (PI/clay } \\
\text { content) }\end{array}$ & 0.63 & 0.80 \\
\hline $\begin{array}{c}\text { BS } \\
\text { classification }\end{array}$ & $\mathrm{CH}$ & $\mathrm{CE}$ \\
\hline
\end{tabular}

\section{Suction and volume change measurement}

There are many techniques for soil suction measurement. Some of them provide direct measurement while others indirect measurements (e.g. using relations between suction and relative humidity). The most commonly used techniques for measuring total, matrix and osmotic suction are filter paper, relative humidity sensors, axis translation and tensiometers. For the research discussed in this paper the primary method of suction measurement was the dewpoint potentiometer (WP4C). Additionally, filter paper technique and tensiometer were used in this research.

The WP4C uses the relative humidity of the air above a sample in a sealed chamber to measure water potential. Once the sample comes into equilibrium with the vapour, relative humidity is determined using the chilled mirror technique. At the dew point, the WP4C measures both mirror and sample temperature within $0.001{ }^{\circ} \mathrm{C}$. The device can measure total suction ranging between $0.1 \mathrm{MPa}$ to $-300 \mathrm{MPa}$ with an accuracy of $\pm 0.05 \mathrm{MPa}$ from 0 to $-5 \mathrm{MPa}$ and $1 \%$ from -5 to $-300 \mathrm{MPa}$ [5].

The principle of the filter paper technique is that the dry filter paper uses its absorption capacity to draw moisture from the soil until the suction in the soil and the paper reach equilibrium. The filter paper can be used for measuring both total and matrix suctions up to 30,000 $\mathrm{kPa}$ the reliable limit of the filter paper [8].

After taking a set of measurement, the discs were dried in stages (incrementally), with a suction measurement made each time, to develop the PDC and PWC of SWRC for each soil. Ideally drying and associated measurement would be continued until the residual state was reached.

\section{Experimental results}

\subsection{Laboratory SWRCs for Sudanese soil samples}

Results of the drying of the reconstituted Sudanese soil measured in the laboratory by WP4C, potentiometer and filter paper are presented in terms of: gravimetric water content and total and matrix suction in Figs 1(a)-1(f). The suction in samples S1 to S4 were measured using WP4C while the suction in other two samples were measured using tensiometer and filter paper. In these figures the drying curve (first drying stage in Fig. 1) defines the PDC, which was continued to the $-300 \mathrm{MPa}$ limit of the WP4C device. The following observations can be made relating to the figures.

There is only one drying stage of six samples shown in Fig. 1, during which measurements were made to define PDC of the SWRCs for the Sudanese sample. Initially the sample was dried, establishing the PDC, which could only be extended to $\mathrm{S}_{\mathrm{r}}=44 \%$ when the limit of the WP4C was reached (Figs 1(a) and 1(b)). 
Measurement of suction is also obtained from tensiometer and filter paper device till they reach their limiting value. The WP4C measurement is more effective beyond $500 \mathrm{kPa}$ while tensiometer and filter paper techniques cover the suction below $500 \mathrm{kPa}$. By combining the three techniques a missing zone is established as shown in Figure (1). At this missing zone, some of important feature such as Air Entry Value $(\mathrm{AEV})$ and its corresponding gravimeter/volumetric water content can be estimated.

In order to produce the full SWRC to residual state, van Genuchten mathematical modelling is used [15]. Van Genuchten's equation is as follows:

$$
\theta=\theta_{f}+\left(\theta_{s}-\theta_{f}\right) /(1+(s / \alpha))^{m}
$$

where: $\alpha, \mathrm{m}$ and $\mathrm{n}$ are experimental constants with controlling the air entry-value (AEV), m controlling the point of infection and $\mathrm{n}$ controlling the slope of the SWRC. $\theta$ is volumetric content and $\mathrm{s}$ is matrix suction or total suction.

These samples started with gravimetric water contents of 70 and $114 \%$ respectively (samples S1 to S4) and eventually equilibrated at values of about $9 \%$ and $13 \%$ for the Sudanese and South African soils, respectively (corresponding to degrees of saturation of $44 \%$ and $59 \%$ ). As these values are very similar to those at the limiting suctions that could be measured, this suggests that a clearly defined sigmoidal form with the associated final residual state would not be reached through simple air drying and that some form of artificial drying or control to reduce the ambient relative humidity around the samples would be necessary.

The PDC is well defined in all representations of the SWRC plotted in terms of the logarithm of suction (Figs 1(b), 1(d) and 1(f)), In terms of degree of saturation, the sample remained almost saturated (i.e. $\mathrm{S}_{\mathrm{r}}=91 \%$ ) to suctions of about $2 \mathrm{MPa}$.

The data in these figures come from three different techniques, WP4C, tensiometer and filter paper. By pairing the three measuring techniques, a clear SWRC is established till the WP4C reaches its limiting value. Beyond the limitation of WP4C, van Genuchten mathematical modelling is used to complete the PDC to theoretical residual stage as shown in Figure 1(g). This fitting technique utilised the method of weighted least squares. The unknown 'parameters' $\alpha, \mathrm{n}$ and $\mathrm{m}$ can be determined from van Genuchten's equation by using the following procedure. First initial values were assumed for these parameters, and then by using the method of least squares these parameters were corrected until reasonable fits to the experimental curves were achieved. This method was carried out using an excel spreadsheet solver which performed the operation. The shape of the resulting curve generated was generally able to model the experimental data well.

Results from the first drying stage used to generate the PDC are plotted in terms of volume change, expressed as void ratio, e, against gravimetric water content in Fig. 1(c). The form of the data expressed in this way is often referred to as a shrinkage curve. These results data are combination of three different measurements and are fit well on the shrinkage curve. There are three stages during drying of the Sudanese soil. The first is a saturated stage when any loss of water volume $\left(\Delta \mathrm{V}_{\mathrm{w}}\right)$ is equal to the reduction in overall volume $(\Delta \mathrm{V})$. A transition stage follows; linking saturated and shrinkage limit stages, when the loss of water volume is greater than the reduction in overall volume $\left(\Delta \mathrm{V}, \Delta \mathrm{V}_{\mathrm{w}}\right)$ and the sample becomes unsaturated. The third, shrinkage limit stage, corresponds to when the sample stops shrinking and the overall volume is not affected by any further loss of water: any loss of water volume is reflected by an equal change in air volume $\left(\Delta \mathrm{V}_{\mathrm{w}}=\Delta \mathrm{V}_{\mathrm{a}}\right)$. It can be observed from Fig. 1(c) that the Sudanese soil has a clearly defined saturated stage at the start of drying: the saturation line $\left(\mathrm{S}_{\mathrm{r}}=100 \%\right)$ drawn is based on the appropriate value of specific gravity, $G_{s}=2.54$. The Sudanese soil shrinkage curve diverges from the saturation line at a water content of $35.0 \%$ and void ratio of 1.00 . The water content at the shrinkage limit is $18.0 \%$ and void ratio 0.50 .

During the first drying, initially the form of the SWRC in terms of void ratio (Fig. 1(d)) is similar to compression curves from an oedometer test where effective stress is progressively increased by a corresponding application of total stress. When drying a sample to generate an SWRC, compression occurs due to progressively increasing suctions with no directly applied total stresses. These processes agree with the concepts of hydraulic and mechanical wetting suggested by [3]. A marked change in compression is observed at about $2 \mathrm{MPa}$ and towards the end of the measured PDC the void ratio becomes constant as the shrinkage limit is approached at $\mathrm{e}=0.50$ (Figs 1(c) and 1(d)). Further loss of water does not cause any decrease in volume, as by this stage the soil particles are held in position by interparticle forces from water menisci.

Axial, radial and volumetric strains $\left(\varepsilon_{\mathrm{a}}, \varepsilon_{\mathrm{r}}\right.$ and $\left.\varepsilon_{\mathrm{v}}\right)$ that developed during the first drying of the Sudanese disc samples are plotted against total suction in Fig. 1(e).

Very rapid increases in strains are evident as suctions increase to about $2 \mathrm{MPa}$, with axial and radial strains reaching about 50 to $75 \%$ of their final values The paths shown in Fig. 1(e) are generally smooth, developing with increasing suction, albeit very gradually for the later stages of drying. Slightly greater axial than radial strains developed initially in the Sudanese sample, after which they tended to converge with increasing suction towards the shrinkage limit, reaching a limiting value of about $18 \%$.

Changes in volumetric strain $\left(\varepsilon_{\mathrm{v}}=\varepsilon_{\mathrm{a}}+2 \varepsilon_{\mathrm{r}}\right)$ take place quite rapidly up to a suction of about $2 \mathrm{MPa}$, as with axial and radial strains, as would be expected. The volumetric strain levels off at about $65 \%$ from a suction value of about $84 \mathrm{MPa}$, which corresponds to that observed at the shrinkage limit in Figs 1(c) and 1(d).

Gravimetric water contents reduce steadily during the first drying (samples S1 to S4) from $70 \%$ to $9 \%$ at the limit of the dewpoint suction measurement. Although not shown, a similar response was observed in terms of volumetric water content $\left(\theta_{\mathrm{w}}\right.$ reducing from $75 \%$ to $16 \%)$. 


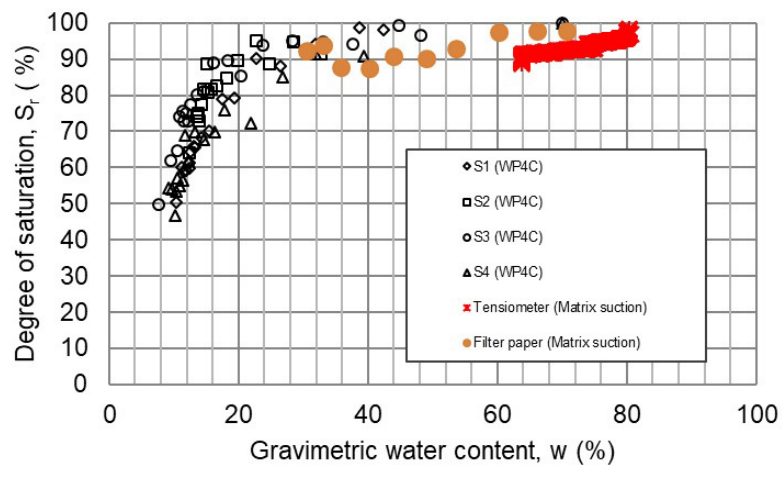

(a)

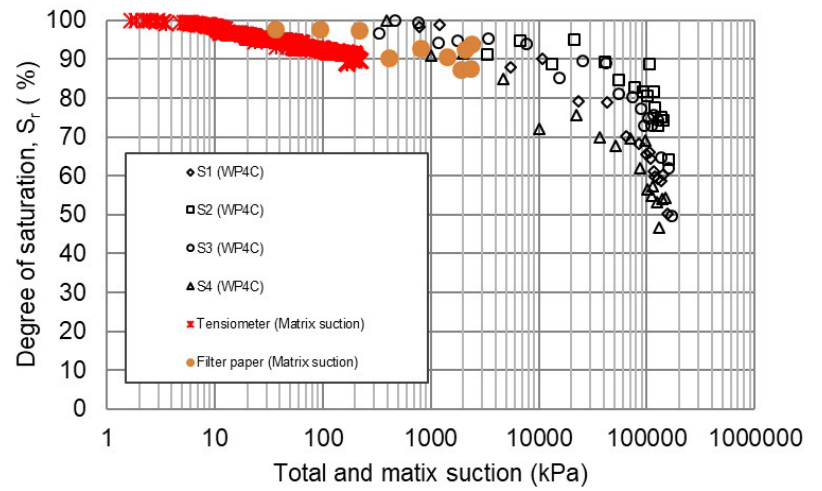

(b)

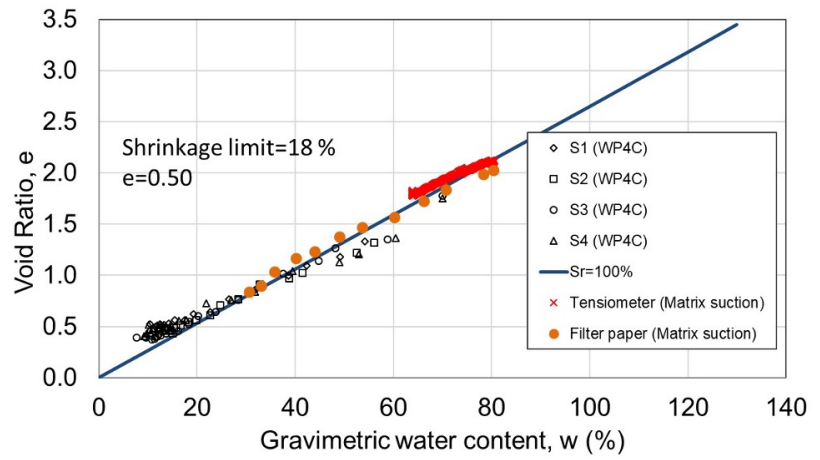

(c)

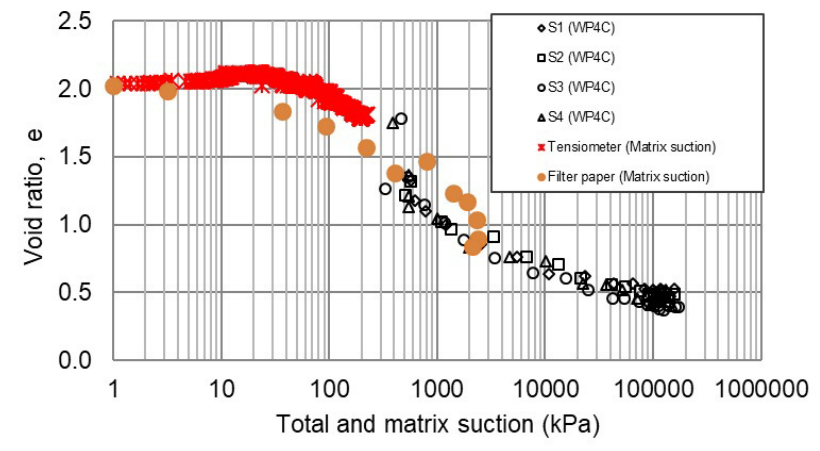

(d)

\subsection{Laboratory SWRCs for South African (SA) soil samples}

Similar sets of plots to those discussed for the Sudanese soil are presented in Figs 2(a)-2(g) for SA soil samples. Trends in sample behaviour are generally very similar to those of the Sudanese soil. As the SA soil is more plastic

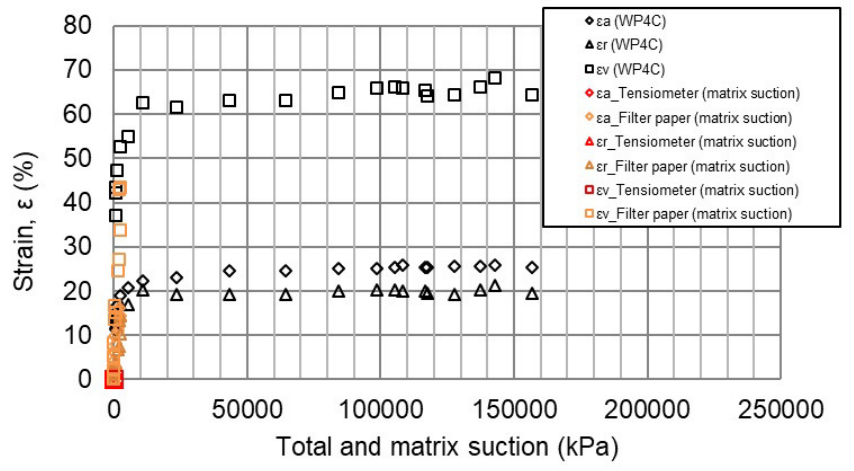

(e)

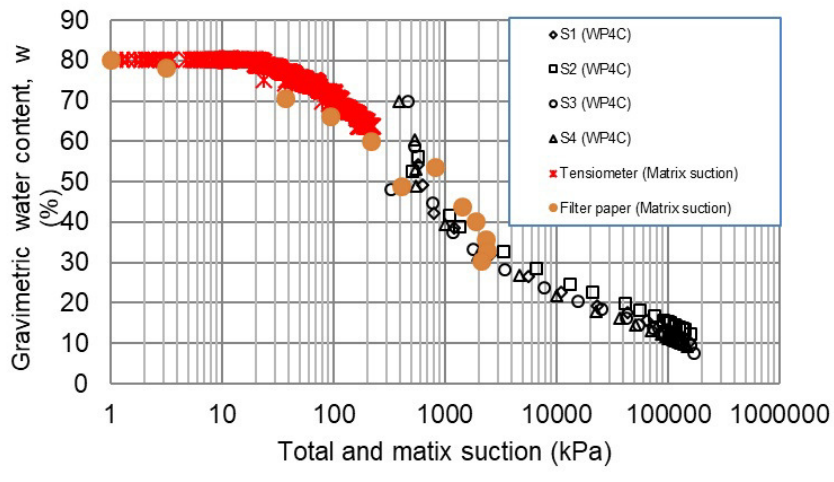

(f)

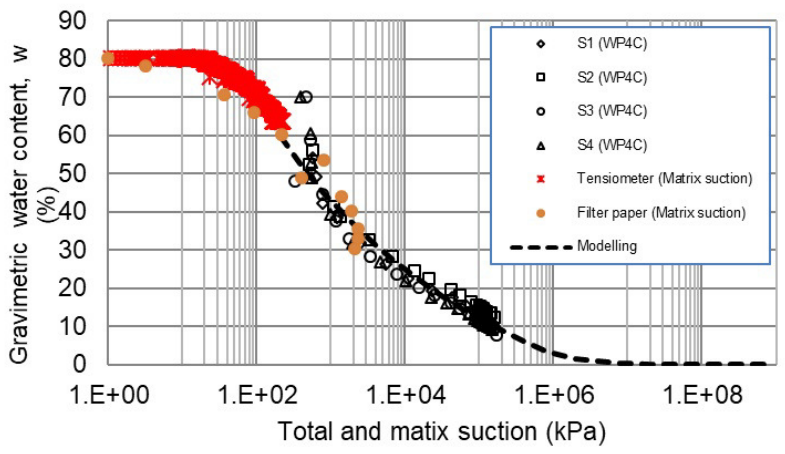

(g)

Fig. 1. SWRCs for the phase of drying of a reconstituted sample of the Sudanese soil plotted in terms of: (a) w against $S_{r}$; (b) $s$ against $\mathrm{S}_{\mathrm{r}}$; (c) w against e; (d) s against e; (e) s against $\varepsilon$; (f) $\mathrm{s}$ against $\mathrm{w}(\mathrm{g})$ van Genuchten model of data experimental.

with a greater fines content, greater suctions are generated at comparable stages and the degree of saturation was higher at the limit of the dewpoint method $\left(\mathrm{S}_{\mathrm{r}}=59 \%\right.$ compared with $44 \%$ for the Sudanese soil).

Differences between responses of the two soils are discussed below. 


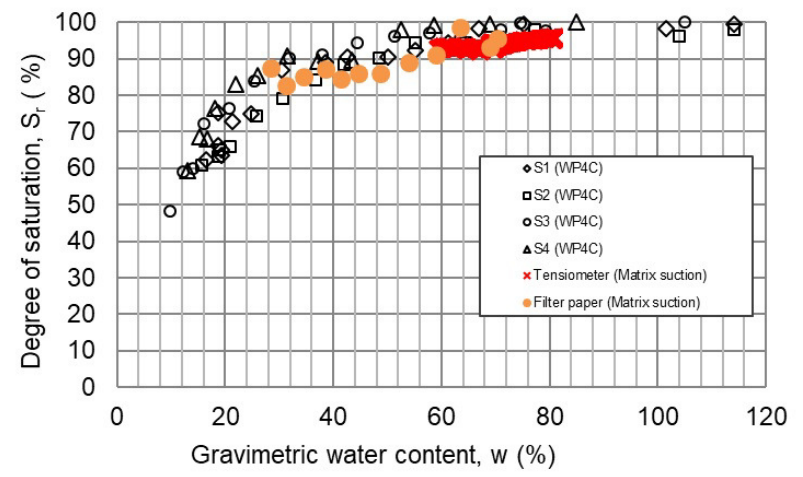

(a)

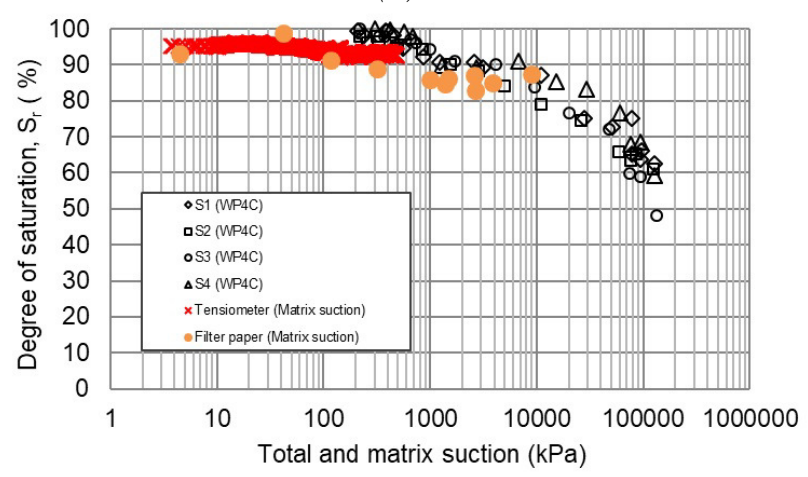

(b)

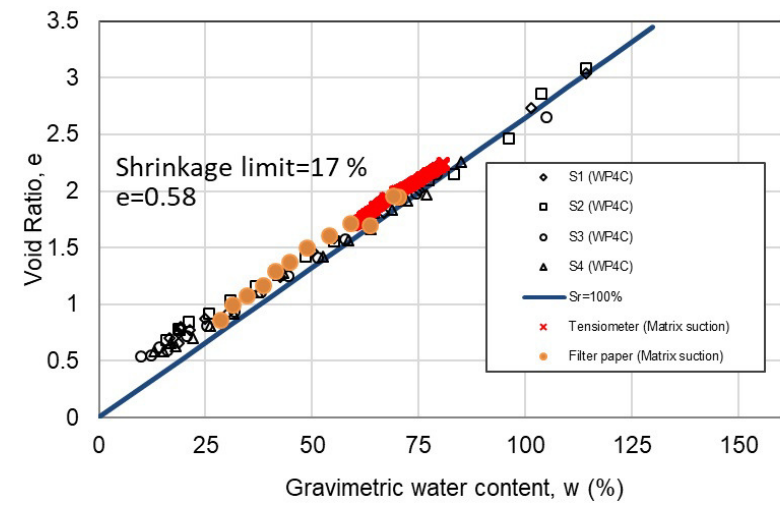

(c)

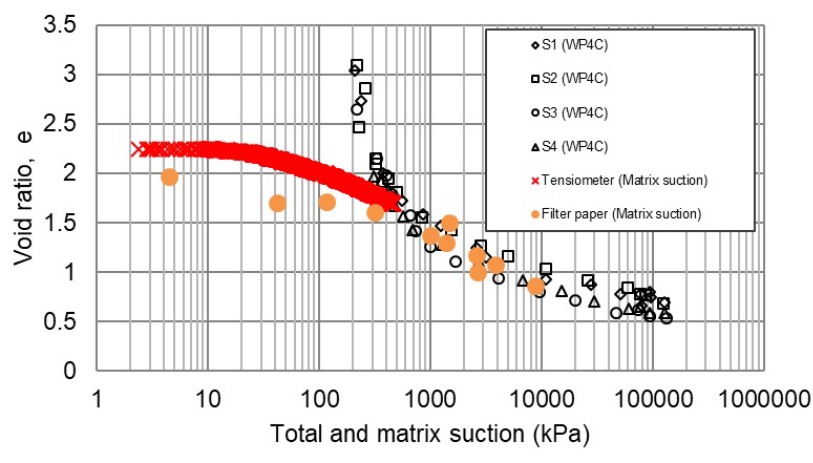

(d)

(a) One drying cycle was measured for the SA soil, the first drying path being the PDC and extending to the limiting suction of $-300 \mathrm{MPa}$.

(b) The SA soil remained almost saturated to much higher total suctions $\left(\mathrm{S}_{\mathrm{r}}=90 \%\right.$ at $\left.\mathrm{s}=7000 \mathrm{kPa}\right)$. No cracking initiated while the sample was dried.

(c) The shrinkage curve for the SA soil (Fig. 2(c)) follows the saturation line (based on $\mathrm{G}_{\mathrm{s}}=2.65$ ) for a

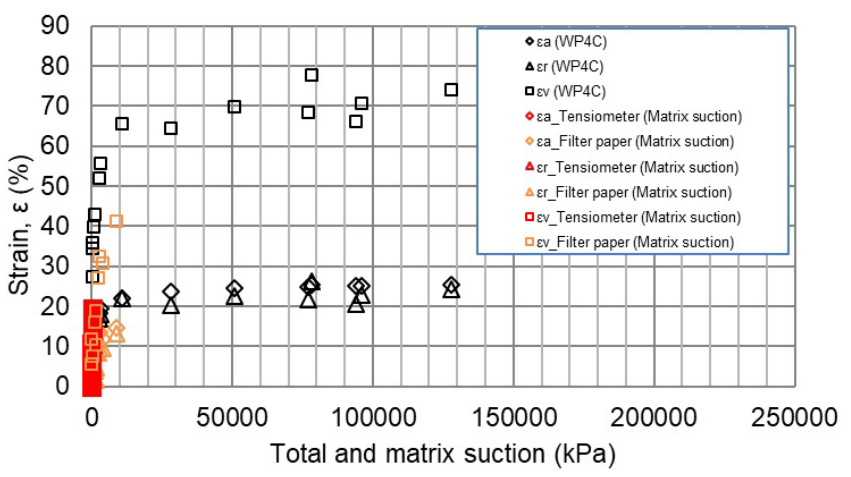

(e)

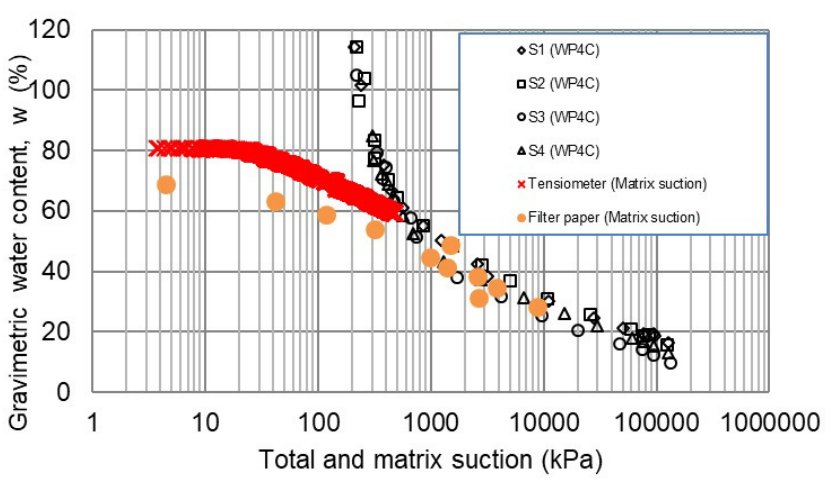

(f)

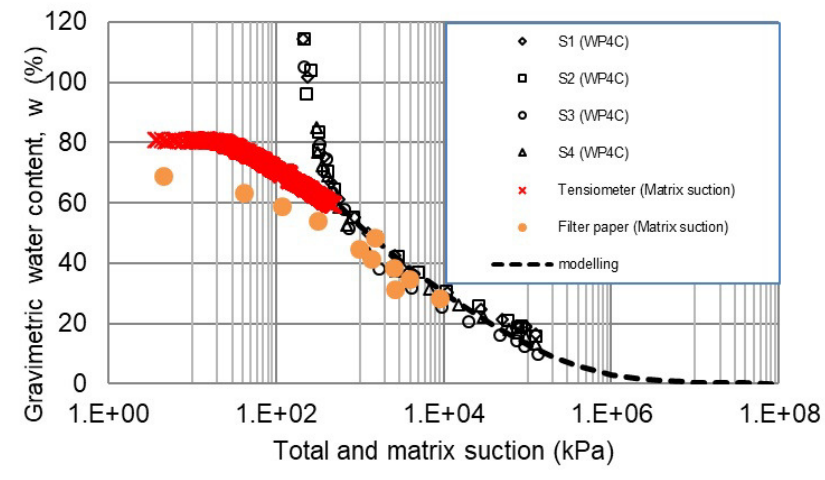

(g)

Fig. 2. SWRCs for phase of drying of a reconstituted sample of the South African soil plotted in terms of: (a) w against Sr; (b) s against $\mathrm{Sr}$; (c) w against e; (d) s against e; (e) s against $\varepsilon$; (f) s against w (g) van Genuchten model of data experimental.

greater volume change than the Sudanese soil (void ratio (samples S1 to S4) reducing from 3.05 to 0.58 , c.f. 1.85 to 0.50 for the Sudanese soil).

This is due to the greater fines content of the SA soil (Table 1), agreeing with the experimental results of [11], who showed that soils with high clay content remain saturated over a wide range of water contents during desiccation. The $\mathrm{SA}$ soil remains saturated $\left(\Delta \mathrm{V}=\Delta \mathrm{V}_{\mathrm{w}}\right)$ 
until the shrinkage limit is reached $(\mathrm{w}=17.0 \%$ and $\mathrm{e}=0.58$ ) with an abrupt transition.

(d) The SA soil has a higher initial void ratio than the Sudanese soil $\left(\mathrm{e}_{0}=3.05\right.$ c.f. $\mathrm{e}_{0}=1.85$ for the Sudanese soil), decreasing steeply to 0.58 at the limit of the drying measurement (c.f. 0.50 for Sudanese soil). Again the shrinkage limit is well defined (Figs 2(c) and 2(d)).

(e) Strains in the SA sample are greater than those of the Sudanese sample because of its greater fines content (Fig. 2(e)). Again sharp increases in strain occur up to about $100 \mathrm{MPa}$, representing about 80 to $95 \%$ of their final values. The initial dimensions of the Sudanese and SA samples were essentially the same at the start of the drying. However, the SA sample developed greater axial than radial strains initially, in contrast to the response of the Sudanese soil. Axial and radial strains converge at a suction value of about $100 \mathrm{MPa}$.

(f) The gravimetric water content of SA soil (Fig. 2(f)) starts at $114 \%$ when measured with WP4C and $80 \%$ when measured with tensioner and both coverage at about $60 \%$ and reduces to $13.0 \%$ (c.f. $70.0 \%$ and $9.0 \%$ for the Sudanese soil) and, although not shown, the volumetric water content has initial and final values of $75.0 \%$ and $17.0 \%$ (c.f. $75.0 \%$ and $16.0 \%$ for the Sudanese soil).

(g) Similar trends in total/matrix suction occur (Figs 2(a), 2(c) and 2(e)) as for the Sudanese soil.

\section{Conclusions}

In this study, SWRC has been produced by pairing of three suction measuring techniques, a tensiometer, a dew point potentiometer (WP4C) and filter paper. An extensive set of SWRCs has been determined for two high-plasticity, tropical soils using reconstituted samples. Total suctions were measured using the dewpoint device technique, allowing drying to be continued to its limit of $-300 \mathrm{MPa}$ and matrix suctions were measured by tensiomter and filter paper to their limits. van Genuchten's model was chosen to fit the laboratory data using least squares method.

Having such a wide range of SWRCs has allowed the influence of initial void ratio and structure to be investigated. Observations on sample dimension changes have also been presented. The main conclusions from the study are as follows.

(a) Consistent SWRC can be developed from combination of WP4C, tensiometer and filter paper irrespective of sample preparation especially at high suction ranges.

(b) For the reconstituted samples both Sudanese and SA soils show a clear first drying (PDC) (in terms of degree of saturation and volume change). Comparisons with the findings from microstructural studies [7] suggest that aggregations formed during the initial drying stage, similar to those observed with samples.

(c) The dewpoint limit meant that final suctions measured corresponded to degree of saturation values of only $44 \%$ and $59 \%$ for the reconstituted Sudanese and SA soils, respectively. In order to investigate this further, reconstituted samples were left to dry and equilibrate at a laboratory temperature. Final degree of saturation values were found to be similar to those at which the limit of the dewpoint technique was reached, suggesting that for high-plasticity clays the sigmoidal form of SWRC usually expected might not develop under moderate climatic temperatures.

(d) Shrinkage curves plotted for the Sudanese and SA soils (in terms of void ratio against water content) are slightly different, with the Sudanese soil following three stages of drying (fully saturated, partly saturated and shrinkage conditions) whereas for the SA soil petite intermediate stage between fully saturated and shrinkage conditions was observed (Fig. 1(c) and Fig. 2(c)).

For both soils, the majority of volume changes occurred in the early stages of first drying, up to total suctions of $2 \mathrm{MPa}$ for the Sudanese soil and $100 \mathrm{MPa}$ for the SA soil (Fig. 1(e) and Fig. 2(e)).

\section{Acknowledgments}

Financial support for this research was provided by the UK Engineering and Physical Sciences Research Council (EPSRC) Global Challenges Fund under the Wind Africa project, Grant Ref: EP/P029434/1. This support is gratefully acknowledged. The authors wish to thank the technicians at Schofield Centre for their help.

\section{References}

1. A. M Ridley, K. Dineen, J. B. Burland, P. R. Vaughan. Soil matrix suction: some examples of its measurement and application in geotechnical engineering. Géotechnique 53, No. 2, 241-253 (2003).

2. A. Tarantino, S. Tombolato. 'Coupling of hydraulic and mechanical behaviour in unsaturated compacted clay', Géotechnique 55(4), 307-317 (2005).

3. A. Tarantino. A water retention model for deformable soils. Géotechnique 59, No. 9, 751-762 (2009).

4. A. Tsiampousi, L. Zdravkovic, D. M. Potts. "A three-dimensional hysteretic soil-water retention curve, Géotechnique 63 (2), 155-164, (2013).

5. D. Devices. WP4C Dewpoint potentiometer, operator's manual. Decagon Devices Inc (2015).

6. D. G. Fredlund, H. Rahardjo, M. D. Fredlund. Unsaturated soil mechanics in engineering practice. Hoboken, NJ, USA: John Wiley \& Sons (2012).

7. E. Romero, G. Della Vecchia, C. Jommi. An insight into the water retention properties of compacted clayey soils. Géotechnique 61, No. 4, 313-328 (2011).

8. F. A. M. Marinho. Shrinkage behaviour of some plastic soils., $\mathrm{PhD}$ thesis, Imperial College London (University of London), UK (1994)

9. G. Fredlund, Delwyn, R. Norbert Morgenstern. "Stress state variables for unsaturated soils." Journal of Geotechnical and Geoenvironmental Engineering 103, no. ASCE 12919 (1977). 
10. G. L. Wheeler, E. W. Trotter, I. W. Dawes, C. M. Grant. Coupling of the transcriptional regulation of glutathione biosynthesis to the availability of glutathione and methionine via the met 4 and yap1 transcription factors', Journal of Biological Chemistry 278(50), 49920-49928 (2003).

11. J. J. B Bronswijk. Modeling of water balance, cracking and subsidence of clay soils. J. Hydrol. 97, No. 3-4, 199-212 (1988).

12. K.M.A. Al Haj, J. R Standing. Mechanical response of two plastic clay soils from Sudan. Géotechnique 65, No.4, 258-273, (2015).

13. K.M.A. Al Haj, J. R Standing. Soil water retention curves representing two tropical clay soils from Sudan. Géotechnique 66, No. 1, 71-84 (2016)

14. K.M.A. Al Haj. Mechanical response of two plastic clay soils from Sudan. PhD thesis, Imperial College London, UK (2014).

15. M. T. van Genuchten. A closed-form equation for predicting the hydraulic conductivity of unsaturated soils. Soil Sci. Soc. Am. J. 44, No. 5, 892-898 (1980).

16. R. J. Chandler, C. I. Gutierrez. The filter paper method of suction measurement. Géotechnique 36, No.2, 265-268, (1986). 